Journal of Social and Development Sciences

Vol. 2, No. 6, pp. 266-274, Dec 2011 (ISSN 2221-1152)

\title{
Organizational Commitment of IT Professionals in Public Sector
}

\author{
*Zahid Mehmood Awan, Sayed Fayaz Ahmed, Muhammad Khalil Shahid \\ Institute of Communication Technologies, NWFP University of Engineering \& Technology, Peshawar, Pakistan \\ *zmawan1968@yahoo.com
}

\begin{abstract}
This study focuses on the factors like salary/incentives, interpersonal conflicts, employeesorganization interface, job satisfaction and organizational culture, in order to clarify the behavior of organizational commitment among information technology employees in public sector organizations. The study provides an insight of the culture of public sector organization, which managers may use for the improvement of organizational commitment. The study tested and analyzed the proposed model, which gave valuable results. The result of the study also claims that organizational commitment may be increased.
\end{abstract}

Key words: Organizational commitment, IT professionals, Public sector

\section{Introduction}

Employees of information technology are the most important component of the government sector organization as they have the ability to solve and manage the complex problem and do the most important job. Information technology jobs play a vital role in service delivery and manage complex programs. Researches have also shown that information technologies jobs positions are more responsible in public sector than in private sector due to accountability, management of information system across agencies and many other reasons that tries not to allow the public sector organization to implement new technologies. This makes them and keeps them under ultimate pressure to perform their jobs and minimize their commitment to organization (Reid, Allen, Reimenschneider and Armstrong, 2001).

Further more there is an increase than yesterday in the demand of information technology employees due to the use of internet, internet based business, electronic marketing and global antagonism. This results in high turn over intentions and low organizational commitment among the information technologies employees. In addition to this, the companies' dependencies on information technologies employees increase the effort to find such competent information technologies employees, which fulfill the requirements of the organization (Ritu and Ferry, 2001). In the above discussed environment, it is important to understand that why professionals of information technology come to organization and leave organization. These phenomenon arias the questions that what are the main factors which make them to join and quit. The biggest issue faced by the organizations is to attract and keep the skilled professional but this is not focused yet. There are some other factors like development in technology, characteristics of jobs, organizational culture also plays an important role in drawing and keeping information technology professionals (Neiderman and Summer, 1997). Another reason is the issue of salary and incentives which are not enough as they aspect from the organization (Burn, Eagamia, Louis, and Poon, 2000). These factors clarifies that the turn over ratios is high in those employees who are new in their career.

The intentions of joining an organization and leaving an organization is a very composite phenomenon which differs from employees to employees due to some one cultural background, different behavioral factors, career stages and other personal personality factors. In short, this study is focus over the factors like salary/incentives, interpersonal conflicts, employees-organization interface, job satisfaction and organizational culture, in order to clarify the behavior of organizational commitment among information technology employees in public sector organization. Public sector organizations have not many resources as compared to private organizations. Therefore, they cannot keep IT professionals satisfied as compared to Private sector organizations. This research will analyze the main factors effecting Organizational commitment in public sector organizations, which reduces Turn over in any organization. The main objectives of the study are: to find out how job satisfaction is affected by Salary and incentives, to find out the effect of job satisfaction over organizational commitment, to find out how turnover intention can be reduced in public 
sector organizations and to find out how employees-organizational interface effect organizational commitment.

\section{Literature Review}

The aim of this research is to find out the main factors which influence the organizational commitment is and how to increase the organizational commitment among the information technology employees. This study takes salary/incentives, job satisfaction, organizational culture, interpersonal conflict of the employees, and the individual organization interface into account to fulfill our study in better way. The following lines will explain each of the factors; we are taking in our research.

Job satisfaction: Job satisfaction is one of the most important factors regarding to the commitment of organization (Lawler, 1992). Employees are satisfied if they work in such an environment, which gives them self-esteem. Employees who are getting greater self-esteem from their work will develop positive attitudes about the organization, which will enhance them to stay within the organization for long term (Korman, 1970). More than this, organizational commitment shows the liking of a job of an employee and sincerely emotional touch to the organization (Mitchell et al. 2001). If there is a satisfactory relationship between the employees and his/her job environment, he/she will prefer to stay in the organization rather than to quit. In addition, that organization which satisfies the needs of their employees is more likely to develop commitment to the organization in them (Steers, 1977). Furthermore, employees may also point out the positive outcomes to their bosses about their jobs (Lincoln and Kalleberg, 1990). The acknowledgment will stimulate these employees to hold encouraging attitudes and will show productive behaviors according to the organization (Rusbult et al. 1988).

Finally, attitudinal studies prove that attitudes are the result of behavioral intentions (Ajzen, 2001). As job satisfaction is also an attitude, which is the result of job condition and its environment, it is strongly connected to the organizational commitment (Spector, 1997). There is also a negative link between Job Satisfaction and turn over Intention in the and TIs has been well established in the text (Mulki et al. 2006). The above literature survey clarifies job satisfaction is an attitudes and is due to some behavior of employees. Therefore, the organization has to control over certain attitudes of its employees and fulfill the need of controlling such a behavior, which result negativity. The organization should also establish with the employees the best possible happy relationships so that it improves the loyalty to the organization and increase the satisfaction of jobs. The organization may also increase job satisfaction among its employees through properly fulfilling the needs and demands of its workers. Organizational commitment is totally based over the job satisfaction and if the employees are satisfied, they will obviously more commit to their organization. We have also assumed this positive relationship between job satisfaction and organizational commitment.

\section{Hypothesis 1: Job satisfaction increases organizational commitment}

Interpersonal Conflicts: Interpersonal conflict is defined as the employee's negative group relations with his/her fellow workers (Penney and Spector, 2005). A situation in which people or group of people have different opinion about some physical substance or over emotional issues leading to the creation of opposition between them. Inter-personal conflict is a common conflict in many organizations, which occurs among the employees. In addition, if there is an honest dissimilarity of opinion, in a case when there are two or more alternatives among the parties having a conflict, then this is called in the sense of an honest difference of opinions, this is called constructive conflict and is very necessary for the development of the organization. In addition, it brings completion and fruitful changes in the organization. Conflict is powerful tool for creativity and offers to think about more than one possibility, which were, ignored earlier.

As we discussed that conflict may be very beneficial for the organization, it may become very dangerous when some one take it for his/her personal glory and its intensity increases with the increase of personal interest. Further, more, the damaged result of the conflict is the production of emotional manifestations among the employees. Some other results of destructive conflict in employees are absence, lateness and turnover intentions or lessen organizational commitment. Further, more, some researchers have found that 
interpersonal conflict mostly results in harmful emotions and approaches of dissatisfaction of job (Fox et al. 2001). Here in our research we also consider destructive interpersonal conflict, having negative affect over job satisfaction and organizational commitment.

In summary there are two result of interpersonal conflict, the first one is positive if the origin, intensity of the conflict is positive, and the other one is negative if the origin and intensity is out of the organizational interest. We are also considering the negative aspect of interpersonal conflict in our research. If the conflict between two employees cross the boundary of organizational interest and enters into the will of employees, it will be for sure harmful for the organization. So if the organization wants to lessen the interpersonal conflict among the employees, it is needed to clearly define its code of conduct, ethics and rules for the organization. In addition, the bosses should also behave equally positive with all the workers. There should be same paying policy for all of the employee and same reward or punishment system for all workers of the firm. We have been considering this negative aspect of interpersonal conflict in our research and create a hypothesis like that:

Hypothesis 2: Interpersonal conflict has negative relationship with job satisfaction

Salaries/Incentives: Maintaining of brilliant workers is very advantageous for a firm but it faces some big challenges while keeping these workers (Barney 1991). In an ideal environment of an organization, employees having good experience are welcomed everywhere as those having low performance ability to listen good-bye from various organizations. The future of any organization is linked with its talented workers and if they leave the organization, it may be a big loss for it. Good performer workers often leave a firm due to their minimum salary (Coff, 1997). Talented and confident workers also may change their organization for more and more opportunities. Usually in that case where, talented and non-talented workers are paid and rewarded the same way. This case then results and encourages the high performers to quit the job and encourage the low performers to stay in the firm. In addition, if the managers fail to evaluate the contribution of employees according to their ability and performance, then they will obviously pay the workers the same amount and it makes it more problematic to keep the talented workers (Simon, 1976).

There are many rationales related to the efficiency of high salaries. In addition, Salaries, which are in good amount, may make a good and valuable payment to the productivity for a specific job (Weiss, 1980). High salaries also encourage the employees' commitment to the organization (Salop, 1979). Some efficiency salaries or wages theories consider the high salaries beneficial because it will also increase the morale of the firm. Some theories believe that high salaries are the main sources for enhanced cooperation. The models, proposed by the sociologists (Akerlof, 1984) and economists (Akerlof and Yellen, 1990), mainly support these. High salaries and other incentives are very necessary for keeping competent workers for long time in an organization. It is a fact that competent workers will demands high pay and incentives from the organization they work in. so if an organization wants to maintain its competitive position in the market and performance, it must offers handsome pay and other incentives for its employees that will increase the job satisfaction of the employees and return much greater commitment to the organization. Based on the above researches we write the following assumption.

Hypothesis 3: Salaries/incentives effect the organizational commitment positively

Organization is Culture: Most of the authors define the organization culture as a main aspect in which the organization is functioning (Hofstede et al. 1990) and is holistic, flexible, and hard to change, having a historical basis, and is collectively created. This definition develops the further explanation of the culture of organization that it is made by the people of the organization according to their beliefs, thoughts and expectations. More over it tends to be specific for specific organization. Organization's culture is that aspect which affects all the other aspects in organization practically like the interaction of people, their dress, and their performance and decisions type made in an organization and policies, procedures of the organization (Buono et al. 1985). The formation of Organization's culture is only dependent on the people who found an organization and those who are the current leaders of an organization and a reaction to external important events (Gordon, 1991). Managers are taking a keen interest in studying the culture of an organization (Jreisat, 1997). Although there are many other reasons, but the main reason is that the organization culture is an 
essential part of the effectiveness of the organization (Denison, 1990). It specialty increases the motivation of the managers to take a keen interest in understanding, monitoring, and managing their organization's culture (Davies and Phillip, 1994). The importance of organization's culture strengthens the path to investigate it in both Public and Private sector organization. In addition, there is more pressure on the government to improve efficiency in running its organization, which needs a change the culture inside these firms (Valle, 1999).

Culture of an organization binds the employees together and develops a sense to work in a group. More significantly, it can serve as an easy understandable method helping the employees to make their behavior in such a way, which is acceptable in an organization (Chatman and Barsade, 1995). Its awareness provides a good direction to the employees to work in an organization (Jreisat, 1997), and to perform in more supportive way to achieve the mission of the organization (Schulz, 2001). Similarity between the culture of organizational and its individual values is linked with more positive attitudes of workers such as commitment to the organizational job satisfaction. There is a difference in the culture of private sector organizations and public sector organizations, which is mainly the result of the environment uniqueness and expectations of the organization (Denhardt, 1991). Now days, there is greater pressure over organizations in public sector to brings changes in their external environment. The managers in these organizations should help their workers to understand these changes and their needs (Valle 1999). In short the impact of the organization culture is clearly plays an important role over those who are experiencing it. More over it is also clear that matched organizational element with it workers will make them satisfied with the organization and hence more committed. This concept is clear to all organization and much of them are trying to change it according to the will of its employees. We would like to consider the relationship between organizational culture and organizational commitment as:

\section{Hypothesis 4: Organizational culture effects the organizational commitment positively}

The Individual-Organization Interface: Researches on job attitudes highlighted the importance of those effects which have strong relation with the organization's characteristic and its employees (Dalton and Todor, 1981; O'Reilly, Chatman, and Caldwell, 1991).Some studies on job studies also gave full concentration over the characteristic of job, employee or upon the organization. Some have also suggested that organizational characteristics have stronger effects over the employees than that of a worker upon the organization (Herman and Hulin, 1972; O'Reilly, Chatman and Caldwell, 1991, O'Reilly, C.A. and Robert, 1975). In their research Flowers and Hughes derived that ethics comes from the own values of a worker as well as the form the condition he/she experiences during the job (Flower and Hughes, 1973). As an organization's standards originate from the societal norms, the way in which its directors take formal decisions, and its policies. So, employees will tend to be in organization until some forces do not motivate him to quit. The greater the gap between the employees and organization standards, the greater will be the forces to leave the organization. In addition, uncertainty decreases the organizational commitment and clarifies ways for individual to attract by the organizational alternatives (Hrebiniak and Alutto, 1972).

Another study also examined in public sector organizations, the effect of organizational standards and values and found that organizational values effects job satisfaction and organizational commitment strongly (Boxx, Dunn and Odom, 1991). In addition to this they also resulted that similarity among these values also affects the behavioral variables. The interaction between employee-organization also has a great effect over the organizational commitment of its workers. Some employees have a spiritual touch with the organization, while some other have a patriotic ambition and so they do not look the other benefits of the organization but remains committed until ends. This phenomenon is strongly related to values, societal norms and policies of the organization and employees personal characteristics. The following assumption comes in my mind to write.

Hypothesis No. 5: Employees-organization interface has a positive effect over organizational commitment 


\section{Figure 1: Structural Model}

Improving Organizational Commitment of IT Professional in Public Sector Organizations

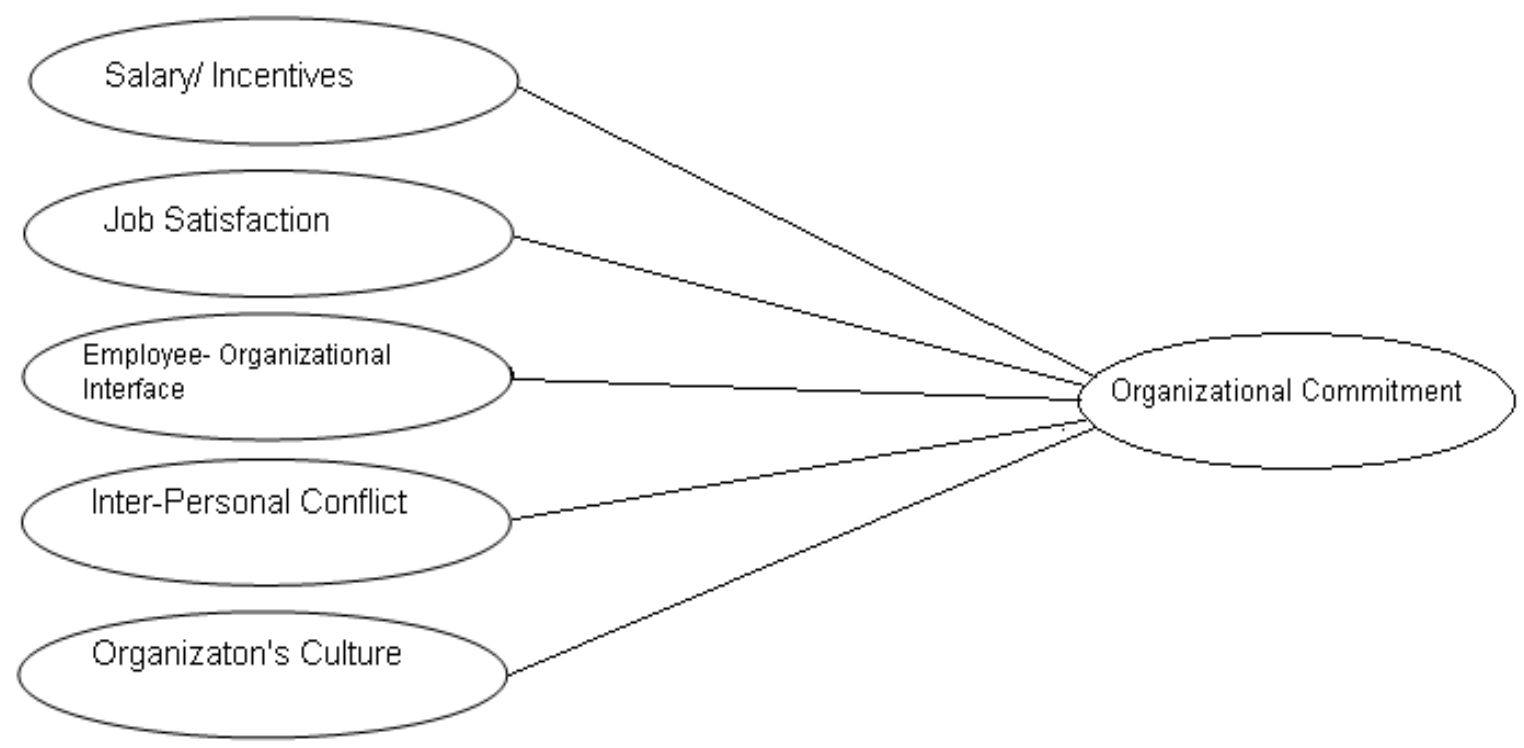

\section{Research Methodology}

There is a big problem in the public sector organization due to its complex structure and professionals from different areas. Organizations pay more to its employees; provide job security to its employees but still lacking organizational commitment in its employees. To find out the various reasons of lacking commitment in the employees, we carried out this research and use the first hand data for it. To the best possible level, we try our best for it is valuably and reliability. The details of the process of the research carried out are given bellow.

Study used hypotheses testing to investigate the relationships among different variables effecting the organizational commitment. Employees of the public sector organizations were supposed to reject or accept the assumption. Before filling out the questionnaire, each respondent were given a brief introduction about the research. The author received 179 questionnaires back from the respondents out of 250 distributed questionnaires were distributed. Random sampling method was used in the survey. The author kept no difference among the employees of the selected organization, based on color, sex, geography, scale, department etc. For a clear and measurable response the author used closed ended question for the research. The questions included in the survey were properly arranged so that justified and valuable data can be collected through it.

\section{Results and Discussion}

This chapter explains the analysis of the data. The data is analyzed with SPSS tools in order to obtain some useful results.

Reliability Test: Before carrying out the analysis reliability test is used with the Cronbach's Alpha value of 0.921 , which is an appropriate value for the data. It means that the questionnaire used in research have produced good results.

ANOVA Test: The results of the ANOVA test describe that there is no significant difference of perception among the groups regarding variables under study. 
Table 1: ANOVA Results

\begin{tabular}{|c|c|c|c|c|c|}
\hline Variables & & $\begin{array}{ll}\text { Sum of } \\
\text { Squares }\end{array}$ & Mean Square & $\mathbf{F}$ & Sig. \\
\hline \multirow{3}{*}{ SI } & Between Groups & .000 & .000 & .034 & .993 \\
\hline & Within Groups & 113.029 & .639 & & \\
\hline & Total & 113.029 & & & \\
\hline \multirow{3}{*}{ JS } & Between Groups & .003 & .003 & .014 & .905 \\
\hline & Within Groups & 39.571 & .224 & & \\
\hline & Total & 39.574 & & & \\
\hline \multirow{3}{*}{ EOI } & Between Groups & .188 & .188 & .394 & .531 \\
\hline & Within Groups & 84.514 & .477 & & \\
\hline & Total & 84.702 & & & \\
\hline \multirow{3}{*}{ IC } & Between Groups & .162 & .162 & .431 & .513 \\
\hline & Within Groups & 66.728 & .377 & & \\
\hline & Total & 66.891 & & & \\
\hline \multirow{3}{*}{ OC } & Between Groups & .814 & .814 & 1.637 & .202 \\
\hline & Within Groups & 87.997 & .497 & & \\
\hline & Total & 88.811 & & & \\
\hline \multirow{3}{*}{ OCT } & Between Groups & .014 & .014 & .029 & .865 \\
\hline & Within Groups & 87.176 & .493 & & \\
\hline & Total & 87.191 & & & \\
\hline
\end{tabular}

Correlations Analysis: For making the findings more effective and precise, the data is also analyzed through correlation statistic and it is found that the data all the variables are positive and significantly correlated to each other

Table No 2: Results of Correlation

\begin{tabular}{llllllll}
\hline Variables & SI & JS & EOI & IC & OC & OCT \\
\hline SI & Pearson Correlation & 1 & & & & & \\
& Sig. (2-tailed) & & & & & & \\
JS & $\mathrm{N}$ & 179 & 179 & 179 & 179 & 179 & 179 \\
& Pearson Correlation & $.609\left(^{* *}\right)$ & 1 & $.675\left(^{* *}\right)$ & $.590\left(^{* *}\right)$ & $.339\left(^{* *}\right)$ & $-.439\left(^{* *}\right)$ \\
& Sig. (2-tailed) & .000 & & .000 & .000 & .000 & .000 \\
EOI & $\mathrm{N}$ & 179 & 179 & 179 & 179 & 179 & 179 \\
& Pearson Correlation & $.65\left(^{* *}\right)$ & $.675\left(^{* *}\right)$ & 1 & $.672\left(^{* *}\right)$ & $.616\left(^{* *}\right)$ & $.556\left(^{* *}\right)$ \\
& Sig. (2-tailed) & .000 & .000 & & .000 & .000 & .000 \\
IC & $\mathrm{N}$ & 179 & 179 & 179 & 179 & 179 & 179 \\
& Pearson Correlation & $.669\left(^{* *}\right)$ & $.590\left(^{* *}\right)$ & $.672\left(^{* *}\right)$ & 1 & $.509\left(^{* *}\right)$ & $.681\left(^{* *}\right)$ \\
& Sig. (2-tailed) & .000 & .000 & .000 & & .000 & .000 \\
OC & $\mathrm{N}$ & 179 & 179 & 179 & 179 & 179 & 179 \\
& Pearson Correlation & $.602\left(^{* *}\right)$ & $.339\left(^{* *}\right)$ & $.616\left(^{* *}\right)$ & $.509\left(^{* *}\right)$ & 1 & $.471\left(^{* *}\right)$ \\
& Sig. (2-tailed) & .000 & .000 & .000 & .000 & & .000 \\
OCT & $\mathrm{N}$ & 179 & 179 & 179 & 179 & 179 & 179 \\
& Pearson Correlation & $.611\left(^{* *}\right)$ & $-.439\left(^{* *}\right)$ & $.556\left(^{* *}\right)$ & $.681\left(^{* *}\right)$ & $.471\left(^{* *}\right)$ & 1 \\
& Sig. (2-tailed) & .000 & .000 & .000 & .000 & .000 & \\
& $\mathrm{~N}$ & 179 & 179 & 179 & 179 & 179 & 179 \\
\hline
\end{tabular}

** Correlation is significant at the 0.01 level (2-tailed). 
Table 3: Results of Regression Analysis

\begin{tabular}{llllllll}
\hline & B & Std. Error & t-Stat & Sig & R-Square & F-Stat & p-value \\
\hline (Constant) & .765 & .275 & 2.778 & .06 & 0.515 & 36.748 & 0.000 \\
SI & .220 & .074 & 2.973 & .000 & & & \\
JS & .102 & .117 & .871 & .000 & & & \\
EOI & .101 & .092 & 1.090 & .000 & & & \\
IC & .529 & .091 & 5.833 & .002 & & & \\
OC & .046 & .073 & .625 & .023 & & & \\
\hline
\end{tabular}

Predictors: (Constant), OC, JS, IC, SI, EOI

Dependent Variable: OCT

In the above table, the result of regression analysis for organizational commitment reveals that the value of RSquare is 0.515 and the F-value is 36.748 . The results show that the model is significant $(p<0.05)$ and there is strong positive relationship between independent and dependent variables. The variables when compared on individual basis, all the variables are significant $(\mathrm{p}<.05)$. Therefore, the model is overall significant at $95 \%$ confidence level and all the independent variables are significantly important for organizational commitment, though with varying degree of importance.

\section{Conclusion and Recommendations}

Conclusion: It is concluded from the results that mostly the employees are agreeing with the factors we included in the research which have a great impact on the organizational commitment of the employees in their organization. The following lines summarize the details of the study. Employees of public sector are found unpleasant from their bosses. Mostly they feel displeasure from them. For making the employees better, these organizations should implement polices and rules which clearly specify the relationship of employee and his boss. Salary is also effecting their commitment with the firm. The salary should be raised by the organization to the limit, which is acceptable in the market. So that it is employees do not quit their jobs due to their salaries. Yet most of the public sector organizations provide job security which increase job satisfaction among the employees but the internal environment of these organization is quite different from the expectations of its employees and there is a need to re-engineer the organizational structure in order to make it more near to the choice of employee and the society in which the organization is operating.

Recommendations: The public sector organization should constitute for authority of a person and position. This will increase the courage of employees to perform well with out hesitations. Also every one will be aware from his/her power and duty. Increase in the salaries of employees will also add a great deal to the problematic areas. The employees will leave job searching out side and will remain committed in the present organization. Introduce the societal values and norms of the operating society inside the organization. With this every employee will think that the organization really value his norms. This will create an emotional attachment of employee with the organization and increase his commitment with the firm. Train its management how to deal with sub-ordinates. Giving training to the managers will inform them from their duties and effective dealing with the employees. Arrange events, which reflect the society norms. Here too, the employees will consider that the organization really cares for them. In addition, their attitude will bind them with the organization.

\section{References}

Ajzen, I. (2001). Nature and Operation of Attitudes. Annual Review of Psychology, 52(1), 27-58. Akerlof, G. A. (1984). Gift Exchange and Efficiency Wages: Four Views. American Economic Review, 74, 79-83. Akerlof, G. A. \& Yellen, J. (1990). The Fair Wage-Effort Hypothesis and Unemployment. Quarterly Journal of Economics, 105, 255-283.

Barney, J. B. (1991). Firm Resources and Sustained Competitive Advantage. Journal of Management, 17, 99120. 
Burn, R., Eagamia, D., Louis, C. \& Poon, B. (2000). Job Expectations of IS Professionals in Hong Kong. ACM Press, New York. 231-24.

Buono, A. F., Bowditch, J. L. \& Lewis, J. W. (1985). When cultures collide: the anatomy of a merger. Human Relations, 38(5), 477-500.

Boxx, W. R., Odom, R. Y. \& Dunn, M. G. (1991). Organizational Values and Value Congruency and Their Impact on Satisfaction, Commitment, and Cohesion: An Empirical Examination within the Public Sector. Public Personnel Management, 20 (2), 1991, 195-205.

Chatman, J. A. \& Barsade, S. G. (1995). Personality, organizational culture, and cooperation: evidence from a business simulation. Administrative Science Quarterly, 40, 423-43.

Coff, R. W. (1997). Human Assets and Management Dilemmas: Coping with Hazards on the Road to ResourceBased Theory. Academy of Management Journal, 22, 374- 402.

Davies, B. \& Philp, A. (1994). Monitoring company culture. Personnel Management, 26(5).

Denison, D. R. (1990). Corporate Culture and Organizational Effectiveness, John Wiley \& Sons, New York, NY.

Denhardt, R. B. (1991). Public Administration: An Action Orientation, Brooks/Cole Publishing, Pacific Grove, CA.

Dalton, D. \& Todor, W. D. (1981). Turnover, Transfer, Absenteeism: An Interdependent Perspective. Journal of Management, 19(2), 193-22.

Flowers, V. S. \& Hughes, C. L. (1973). Why Employees Stay. Harvard Business Review, 51(4), 49-60.

Fox, S., Spector, P. E. Miles, D. (2001). Counter productive Work Behavior in Response to Job Stressors and Organizational Justice: Some Mediator and Moderator Tests for Autonomy and Emotions. Journal of Vocational Behavior 59(3), 291-309.

Gordon, G. G. (1991). Industry determinants of organizational culture. Academy of Management Review, 16, 396-415.

Herman, J. B. \& Hulin, C. L. (1972). Studying Organizational Attitudes from Individual and Organizational Frames of Reference. Organizational Behavior and Human Performance, 8, 84-108.

Hrebiniak, L. G. \& Alutto, J. A. (1972). Personal and Role-Related Factors in the Development of Organizational Commitment. Administrative Science Quarterly, 16, 555-72.

Hofstede, G., Neuijen, B., Ohayv, D. D. \& Sanders, G. (1990). Measuring organizational cultures: a qualitative and quantitative study across twenty cases. Administrative Science Quarterly, 35(1), 286-316.

Jreisat, J. E. (1997). Public Organization Management: The Development of Theory and Process, Praeger, Westport, CT.

Korman, A. (1970). Toward a Hypothesis of Work Behavior. Journal of Applied Psychology, 54, 31-41.

Lawler, E. E. (1992). The Ultimate Advantage: Creating the High Involvement Organization (Jossey-Bass, San Francisco).

Lincoln, J. R. \& Kalleberg, A (1990). A. Culture, Control and Commitment: A Study of Work Organization and Work Attitudes in the United States and Japan (Cambridge University Press, Cambridge).

Mitchell, T. R., Holtom, B. C., Lee, T. W., Sablynski, C. J. \& Erez, M. (2001). Why People Stay Using Job Embeddedness to Predict Voluntary. Academy of Management Journal, 44, 1102-1121.

Mulki, J. P., Jaramillo, F. \& Locander, W. B. (2006). Effects of Ethical Climate and Supervisory Trust on Salesperson, Job Attitudes and Intentions to Quit. Journal of Personal Selling \& Sales Management, 26(1), 19-26.

Neiderman \& Summer, W. (1997). Decision Path Affecting Turnover Intensions among IT professional Workforce ACM Press New York, 11-20.

O’Reilly, C. A., Chatman, J. A. \& Caldwell, D. F. (1991). People and organizational culture: a profile comparison approach to assessing person-organization fit. Academy of Management Journal, 14, 487-516.

O’Reilly, C. A., Chatman, J. \& Caldwell, D. F. (1991). People and Organizational Culture: A Profile Comparison Approach to Assessing Person-Organization Fit. Academy of Management Journal, 34(3), 487-516.

O’Reilly, C. A. \& Robert, K. (1975). Individual Differences in Personality, Position in the Organization and Job Satisfaction. Organizational Behavior and Human Performance, 14, 144-50.

Penney, L. M. \& Spector, P. E. (2005). Job Stress, Incivility, and Counterproductive Work Behavior: The Moderating Role of Negative Affectivity. Journal of Organizational Behavior, 26(7), 777-796.

Ritu, A. \& Ferry, H. (2001). Retention and Career Motives of IT Professionals Workforce, ACM Press New Yook, 158-166. 
Rusbult, C. E., Farrel, D., Rogers, G \& Mainous, A. G. (1988). Impact of Exchange Variables on Exit, Voice, Loyalty, and Neglect: An Integrative Model of Response to Declining Job Satisfaction. Academy of Management Journal, 31(3), 599-628.

Reid, M. F., Allen, M. W., Armstrong, D. J. \& Riemenschneider, C. K. (2001). ACM Press New Yook NY, US 321331.

Salop, S. C. (1979). A Model of the Natural Rate of Unemployment. American Economic Review, 69, 117-125.

Simon, H. A. (1976). Administrative Behavior: A Study of Decision-making Processes in Administrative Organization, New York, Free Press.

Spector, P. E. (1997). Job Satisfaction: Application, Assessment, Causes, and Consequences.

Steers, R. M. (1977). Antecedents and Outcomes of Organizational Commitment. Administrative Science Quarterly, 22(1), 46-56.

Schulz, J. W. (2001). Tapping the best that is within why corporate culture matters. Management Quarterly, 42, 29-35.

Valle, M. (1999). Crisis, culture and charisma: the new leader's work in public organizations. Public Personnel Management, 28(2), 245-57.

Weiss, A. (1980). Job Queues and Layoffs in Labor Markets with Flexible Wages. Journal of Political Economy, $88,526-538$. 